\title{
Mandibular ameloblastoma reconstruction: a case report with 10-year follow-up
}

\author{
Reconstrucción en ameloblastoma mandibular: \\ reporte de caso, con 10 años de seguimiento
}

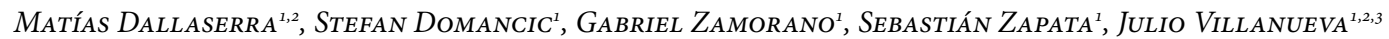

\author{
Department of Oral and Maxillofacial Surgery and Traumatology, Universidad de Chile, Santiago, Chile \\ Cochrane Center Associate, School of Dentistry, Universidad de Chile \\ Maxillofacial Surgery Unit, San Borja Arriar n Clinical Hospital
}

\begin{tabular}{|c|c|}
\hline \multirow[b]{2}{*}{$\begin{array}{l}\text { Keywords: } \\
\text { ameloblastoma, } \\
\text { mandible } \\
\text { reconstruction, } \\
\text { free grafts, case } \\
\text { report }\end{array}$} & Abstract \\
\hline & $\begin{array}{l}\text { Ameloblastoma is a benign dental tumor mostly found in the mandible, with several variations. The treatment } \\
\text { of this pathology ranges from simple enucleation to resection of large sections of the affected bone. There } \\
\text { are several options for correcting the sequelae of ameloblastoma treatment, including the use of grafts } \\
\text { and currently microvascular free flaps, which have become the standard treatment. This report describes a } \\
\text { clinical case of a large mandibular ameloblastoma, which was resected with safety margins about } 10 \text { years } \\
\text { ago, reconstructed by free grafts in successive surgical times and rehabilitated using removable prostheses. } \\
\text { The question is then what the best option is today in the reconstruction of patients affected by this type of } \\
\text { pathologies, taking into account emerging options, the clinicians' learning curve and the patients' resources. }\end{array}$ \\
\hline & \\
\hline $\begin{array}{l}\text { Palabras clave: } \\
\text { ameloblastoma, } \\
\text { reconstrucci n } \\
\text { mandibular, } \\
\text { injertos libres, } \\
\text { informe de caso }\end{array}$ & $\begin{array}{l}\text { El ameloblastoma es un tumor odontog nico benigno que se encuentra mayormente en la mand bula, } \\
\text { existiendo diversas variedades del mismo. El tratamiento de esta patolog a va desde la enucleaci } \mathrm{n} \text { simple } \\
\text { hasta la resecci } \mathrm{n} \text { de grandes secciones del hueso comprometido. Para la correcci } \mathrm{n} \text { de las secuelas por } \\
\text { tratamiento de ameloblastoma existen varias opciones, entre las que se encuentra el uso de injertos y } \\
\text { hoy en d a los colgajos libres microvascularizados, que se han convertido en el est ndar de tratamiento. } \\
\text { El presente reporte pretende mostrar un caso cl nico de un gran ameloblastoma mandibular, el cual fue } \\
\text { resecado con } \mathrm{m} \text { rgenes de seguridad hace alrededor de } 10 \text { a os, reconstruido mediante injertos libres en } \\
\text { tiempos quir rgicos sucesivos y rehabilitado mediante el uso de pr tesis removibles. Se plantea entonces } \\
\text { la pregunta de cu les la mejor opci n hoy en d a en la reconstrucci n de pacientes afectados por este tipo } \\
\text { de patolog as, tomando en cuenta las opciones emergentes, la curva de aprendizaje de los cl nicos y los } \\
\text { recursos de los pacientes. }\end{array}$ \\
\hline
\end{tabular}

Submitted: October 15/2018 - Accepted: March 19/2019

How to quote this article: Dallaserra M, Domancic S, Zamorano G, Zapata S, Villanueva J. Mandibular ameloblastoma reconstruction: a case report with 10-year follow-up. Rev Fac Odontol Univ Antioq. 2019; 31(1-2): 171-177. DOI: http://dx.doi.org/10.17533/udea.rfo.v31n1-2a15

\section{INTRODUCTION}

The following report was done following the CARE guidelines for the preparation of clinical case reporting. ${ }^{1}$

Ameloblastoma is a benign dental tumor originating from epithelial remains of the enamel organ, with most of them (about $80 \%$ ) usually found in the mandible, making up about $1 \%$ of tumors in the oral region. ${ }^{2}$

Chapter 4 of the World Health Organization's (WHO) Head and Neck Tumor Update provides a new classification of dental and 
maxillofacial skeleton tumors. According to this update, ameloblastoma can be classified into the following types: ${ }^{3}$

- Unicystic: characterized by the presence of a single cystic cavity. The previous classification (2005) included a type of solid or multicystic ameloblastoma which was discarded because was considered irrelevant from a biological point of view and created confusion with unicystic ameloblastoma.

- Peripheral: located outside the bone, especially in gingival or alveolar mucosa. It is often mistaken as an irritating fibroid, which can be differentiated by biopsy or by observation of slight bone imprint during this procedure.

- Desmoplastic: in the new classification, it is considered a subtype of histopathological classification and not as a clinical entity. It has a characteristic histology, showing extensive collagenization in its stroma. Radiographically, it has a mixed appearance with fuzzy edges, indicating more aggressive properties than the other two.

The treatment of this pathology ranges from simple enucleation, decompression and marsupialization, to resections of affected bone segments with safety margins. The conservative approach is not commonly used, except in small tumors of the unicystic variant, given the high recurrence rate of the lesion. This is why the treatment of choice is generally the aggressive management of the lesion, ${ }^{4,5}$ which in some cases leads to large tissue loss and its consequences from a functional point of view.

Mandible reconstruction before the emergence of microvascular free flaps was fully based on the use of different flap designs and especially free grafts, mainly iliac crest and tibia, ${ }^{6}$ which generally provide good results, although with some risk of grafts reabsorption, which can be of up to $20 \%{ }^{7}$ and therefore is more significant in greater defects. This has improved with the use of microvascular free flaps, which provide immediate reconstructions by transferring hard and soft tissues and even by installation of osseointegrated implants during the same operating time for extensive dental rehabilitations in patients affected by this and other pathologies that require these types of interventions. $^{4,8}$ However, this procedure is not free of complications and can lead to flap loss, which in the early days of the technique was nearly $40 \%$, but today has improved, with failure rates ranging from $1 \%$ to $9 \%$ according to the literature reports, ${ }^{9,10}$ as shown by the experience of a low-flow center for this type of reconstructions in the United States, which in 20 years achieved $92.6 \%$ of successful transfers. ${ }^{11}$

This article describes the ten-year follow-up of a large mandibular ameloblastoma, which was treated with free graft reconstruction, showing the various stages that were carried out to obtain a result and discussing the outcome in light of what is now considered a therapeutic gold standard in these circumstances: microvascular free flap.

\section{Patient information}

In May 2005, a 19-year-old patient of Hispanic origin was referred to the Maxillofacial Surgery Service of San Borja Arriar n Clinical Hospital due to a mass of 15 months of evolution located in the right perimandibular area, which had been under observation at another hospital for more than 1 year. The patient had no associated comorbidities. Concerning family history, she only referred to her mother's high blood pressure. 


\section{Clinical findings}

The clinical examination showed a soft mass with no skin involvement in the retromolar area, with noticeable bone expansion in the buccal, lingual and mandibular basilar areas.
There was no neurological involvement (mandibular nerve). The X-ray examination showed a mixed density multilocular osteolytic lesion, expanding towards cortical and producing first molar and second premolar root resorption (Figure 1).

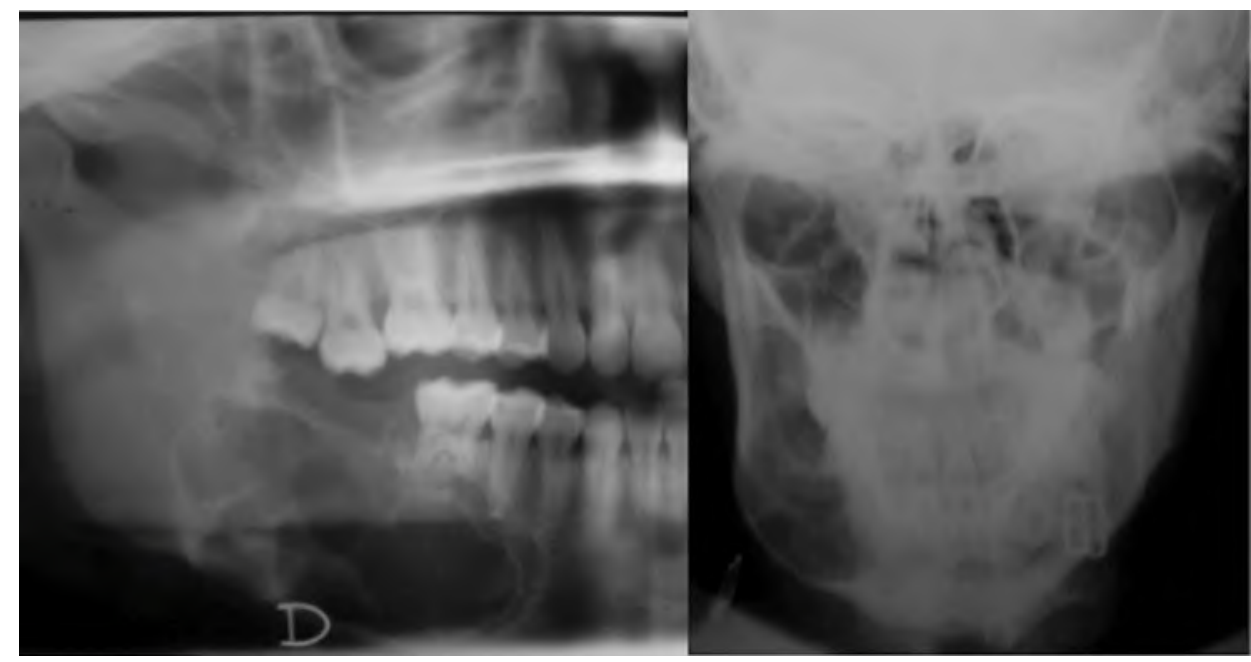

Figure 1. Osteolytic lesion causing rizalisis of 4.6 and 4.5

Source: by the authors

\section{Timeline}

Table 1 shows the timeline of diagnosis, treatment and follow-up of the reported case.

Table 1. Timeline from initial evaluation to 10 year-follow up

\begin{tabular}{|c|c|}
\hline Hospital follow-up & $2004-2005$ \\
\hline $\begin{array}{l}\text { Initial evaluation at Maxillofacial Surgery Service of } \\
\text { San Borja Arriarán Hospital }\end{array}$ & May 2005 \\
\hline Incisional biopsy and diagnosis & May 2005 \\
\hline Resection & June 2005 \\
\hline Reconstruction with iliac crest-free graft & August 2005 \\
\hline $\begin{array}{c}\text { Control and observation of resorption and mandibular } \\
\text { bone defect }\end{array}$ & 2007 \\
\hline $\begin{array}{c}\text { Correction of mandibular bone defect with iliac crest- } \\
\text { free graft }\end{array}$ & 2008 \\
\hline Removal of osteosynthesis material & 2009 \\
\hline Follow up & 2015 \\
\hline
\end{tabular}

Source: by the authors

\section{Diagnostic evaluation}

Taking into account the clinical findings and radiographic characteristics, it was decided to conduct an incisional biopsy, which is the standard gold test for the diagnosis of mandibular bone lesions. The histopathological study showed a conventional plexiform ameloblastoma.

\section{Therapeutic intervention}

Complete resection of the lesion was performed with safety margins from the right canine to the ipsilateral mandibular ramus, inserting a reconstruction plate and reconstructing soft parts. Two months after the initial procedure and with clean margins, mandibular reconstruction was carried out with iliac crest-free grafting. During 
a follow-up 1 year and a half afterwards, resorption of the graft with mandibular continuity was observed. However, one year later, due to the patient's personal reasons, the mandibular defect was corrected by reconstruction with iliac crest-free graft. The osteosynthesis material was removed one year later once the jaw contour continuity had been confirmed (Figure 2).

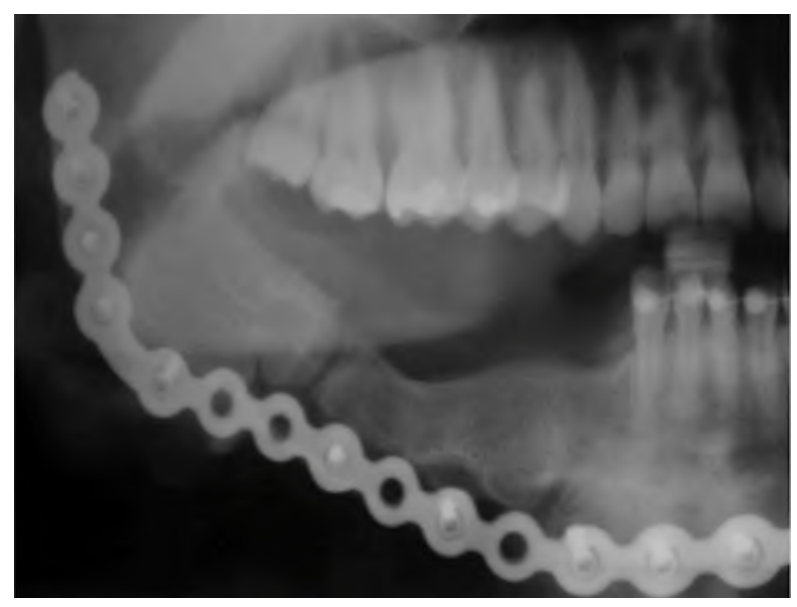

Figure 2. Deferred reconstruction with iliac crest-free grafting

Source: by the authors

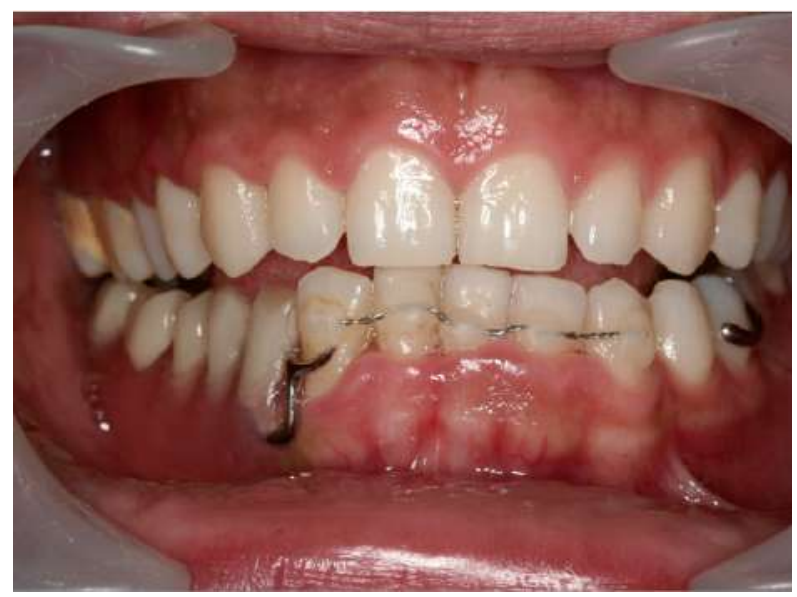

Figure 3. 10-year follow-up

Source: by the authors

\section{Follow up and outcome}

Ten years after being admitted to the service, the patient has referred good adherence to surgical treatment and subsequent follow-up. The mandibular reconstruction is in excellent conditions in relation to the integration of its free graft, functionality and aesthetics. Finally, the removable prosthetic rehabilitation is in place and functional, which was used instead of osseointegrated implants due to financial reasons mainly (Figure 3 ).

\section{DISCUSSION}

The described ameloblastoma treatment is controversial due to the aggressiveness of the tumor, its recurrence, and the morbidity following treatment. This treatment can be either conservative or radical; the former includes therapeutic measures such as enucleation and curettage, requiring less surgical time and patient morbidity, while the latter involves segmental resection, requiring major reconstructive surgery. There is a statistically significant lower recurrence with the radical approach compared to the conservative one. This involves greater mutilation, but relapse and subsequent reintervention are avoided. ${ }^{12}$

One of the strengths of this clinical case is that, thanks to the non-conservative treatment (full resection), no ameloblastoma relapses have occurred as of today. We can also mention that proper patient follow-up allowed us to manage the only complication that arose, consisting of discontinuity resorption of the free graft initially located in the defect by a second iliac crest graft. The difficulties of the case include the extent of the resection due to lesion size, which caused a significant functional alteration. This was not solved with osseointegrated 
implants in the graft, which would have been the ideal solution, but with removable prosthetic rehabilitation due to the patient's economic conditions.

Given the lesion size and considering the reported recurrences in conservative treatments of this type of lesions up to $80 \%,{ }^{4}$ the treatment of choice in this case was full resection with safety margins, which involves the removal of virtually an entire jaw segment. This produces functional alterations in terms of swallowing, chewing and phonation, requiring not only resective surgery, but also reconstruction of lost structures, both hard and soft, as this is what helps provide patients with a good quality of life.

In 2005, when the first interventions were performed in this patient, free bone autografts was the best available therapeutic alternative, with the iliac crest graft being one of the best options. ${ }^{6}$ However, as this was a major defect covering from canine to right mandibular ramus, the risk of existing bone resorption was high, and unfortunately a lack of jaw contour continuity was observed one year and a half after the initial reconstruction; as a result, a second reconstructive intervention had to be conducted, forcing the patient to undergo general anesthesia and another recovery period due to the functional mobility problems caused by taking grafts from both iliac and tibia crests.

Given this situation, and seeking fewer interventions with less morbidity in orofacial functional terms and in donor sites, microvascular free flaps have emerged lately as an alternative, with the literature reporting one single surgical time for both resection and mandibular reconstruction, with good results from the morphofunctional point of view and in terms of quality of life perception by patients treated this way. ${ }^{3,4,13,14}$
The implementation of microvascular free flaps has certainly brought about a series of changes in maxillofacial surgery teams, as it requires some initial formal training, in which the learning curve is rather flat, that is, mastery of the technique requires quite a bit of time to ensure good results. Also, performing the interventions at the same surgical time requires a joint work with another surgical team in charge of taking the graft, as it is not the maxillofacial surgeon's responsibility to perform surgical interventions in areas like the hip or leg. Similarly, the places where the necessary training can be carried out to master the microanastomosis technique in our country are mainly centers dedicated to the treatment of oncological diseases, which again is not part of the maxillofacial surgeon's competency, and therefore there might be resistance by experts in this area to provide guidance to those interested in developing this technique in the best possible way.

However, despite the benefits associated with the use of microvascular free flaps, it is necessary to consider that these have a significant loss rate and therefore require expert hands, which are difficult to find in our context. In addition, they are much more expensive and require more resources compared to the technique used in this case to achieve the patient's functional reconstruction. Thus, in weighing the benefits, risks and costs of both treatments, it is not illogical to lean toward free-bone graft reconstructions despite not being the therapeutic standard, given the predictability of their results, even taking into account the risk of resorption, which can be corrected with a less expensive technique in terms of time and money compared to the implications of losing a microvascular free flap. 
Another important aspect is dental rehabilitation, which in this case had to be performed with a removable prosthetic apparatus for economic reasons mainly. However, the use of such devices necessarily involves the constant application of compressive forces against the grafted bone, which eventually leads to bone resorption. ${ }^{15}$ This is why ideally osseointegrated implants could and should be placed at the time of surgery in order to provide the patient with the best masticatory effectiveness and to offer better expectations regarding the reconstruction permanence in the best conditions and for as long as possible.

Finally, while the traditional techniques ultimately offer excellent results, the emergence of new methods for the treatment of maxillofacial pathology and its subsequent reconstruction must be taken into account and considered by practitioners as a way to challenge or stimulate generations to come in the new fields of study and training of surgical skills, in order to provide patients with the best treatment available, as well as the best expectations and quality of life, always taking into account the benefits, risks and costs associated with the therapeutic options, which should certainly be discussed and decided in conjunction with the patient. This case report proposes that conventional techniques for mandibular reconstruction secondary to the resection of benign pathologies provide advantages compared to the resources used and the excellent results achieved in the long term. However, it suggests new tools and methods for the treatment of these pathologies, such as microvascular free flap, which pose a major challenge for maxillofacial surgeons due to the necessary experience and the low casuistic available to achieve the learning curve.

\section{CONFLICT OF INTEREST}

The authors state that they have no conflict of interest.

\section{CORRESPONDING AUTHOR}

Julio Alberto Villanueva Maffei

Facultad de Odontolog a, Universidad de Chile javm@uchile.cl

Sergio Livingstone P 943 Independencia.

Santiago de Chile. Chile

\section{REFERENCES}

1. Riley D, Barber M, Kienle G, Aronson JK, von Schoen-Angerer T, Tugwell P et al. CARE guidelines for case reports: explanation and elaboration document. J Clin Epidemiol. 2017; 89: 218-35. DOI: https://doi. org/10.1016/j.jclinepi.2017.04.026

2. Masthan KMK, Anitha N, Krupaa J, Manikkam S. Ameloblastoma. J Pharm Bioallied Sci. 2015; 7(Suppl 1): S167-70. DOI: https://dx.doi.org/10.4103\%2F0975-7406.155891

3. Wright J, Vered M. Update from the 4th edition of the world health organization classification of head and neck tumours: odontogenic and maxillofacial bone tumors. Head and Neck Pathol. 2017; (11): 68-77. DOI: https://doi.org/10.1007/s12105-017-0794-1

4. Bianchi B, Ferri A, Ferrari S, Leporati M, Copelli C, Ferri T et al. Mandibular resection and reconstruction in the management of extensive ameloblastoma. J Oral Maxillofac Surg. 2013; 71(3): 528-37. DOI: https:// doi.org/10.1016/j.joms.2012.07.004 
5. Tamme T, Tiigim e J, Leibur E. Mandibular ameloblastoma: a 28-years retrospective study of the surgical treatment results. Minerva Stomatol. 2010; 59(11-12): 637-43.

6. Soto G ngora S, Texis Gonz lez MG. Injertos seos: una alternativa efectiva y actual para la reconstrucci $n$ del complejo cr neo-facial. Rev Cuba Estomatol. 2005; 42(1).

7. Ozaki W, Buchman SR. Volume maintenance of onlay bone grafts in the craniofacial skeleton: microarchitecture versus embryologic origin. Plast Reconstr Surg. 1998; 102(2): 291-9. DOI: https://doi. org/10.1097/00006534-199808000-00001

8. Bak M, Jacobson AS, Buchbinder D, Urken ML. Contemporary reconstruction of the mandible. Oral Oncol. 2010; 46(2): 71-6. DOI: https://doi.org/10.1016/j.oraloncology.2009.11.006

9. Pattani KM, Byrne P, Boahene K, Richmon J. What makes a good flap go bad? a critical analysis of the literature of intraoperative factors related to free flap failure. Laryngoscope. 2010; 120(4): 717-23. DOI: https://doi.org/10.1002/lary.20825

10. Wong AK, Joanna Nguyen T, Peric M, Shahabi A, Vidar EN, Hwang BH et al. Analysis of risk factors associated with microvascular free flap failure using a multi-institutional database. Microsurgery. 2015; 35(1): 6-12. DOI: https://doi.org/10.1002/micr.22223

11. Klosterman T, Siu E, Tatum S. Free flap reconstruction experience and outcomes at a low-volume institution over 20 years. Otolaryngol Head Neck Surg. 2015; 152(5): 832-7. DOI: https://doi. org/10.1177/0194599815573726

12. Hendra FN, Natsir Kalla DS, Van Cann EM, de Vet HCW, Helder MN, Forouzanfar T. Radical vs conservative treatment of intraosseous ameloblastoma: systematic review and meta-analysis. Oral dis. 2018. DOI: https://doi.org/10.1111/odi.13014

13. Tang JA, Rieger JM, Wolfaardt JF. A review of functional outcomes related to prosthetic treatment after maxillary and mandibular reconstruction in patients with head and neck cancer. Int J Prosthodont. 2008; 21(4): 337-54.

14. Zhu J, Yang Y, Li W. Assessment of quality of life and sociocultural aspects in patients with ameloblastoma after immediate mandibular reconstruction with a fibular free flap. Br J Oral Maxillofac Surg. 2014; 52(2): 163-7. DOI: https://doi.org/10.1016/j.bjoms.2013.10.012

15. Sodek J, Mckee MD. Molecular and cellular biology of alveolar bone. Periodontol 2000. 2000; 24(1): 99-126. 